\title{
A Dynamic Analysis of College Students' Strategies in Establishing Identities from the Perspective of Speech Accommodation
}

\author{
Gao-chun MEN ${ }^{1, a, b,{ }^{*}}$ \\ ${ }^{1}$ School of Foreign Languages, Wuhan University of Technology, \\ Wuhan, China, 430070 \\ a24751688@qq.com, ${ }^{\mathrm{b} m e n c y 2001 @ 163 . c o m ~}$
}

\begin{abstract}
Keywords: Speech Accommodation Theory, Identity Establishment, Convergence, Divergence.
\end{abstract}

\begin{abstract}
Based on sociolinguistic Speech Accommodation Theory, this study will take college students as research samples to explore systematically how the interlocutors accommodate to their social identities by adopting various strategies in social communication. Two perspectives will be explored respectively, namely, speech convergence and speech divergence. Two questions will be analyzed systematically: (1) What strategies the college students will adopt in specific contexts to establish their identities? (2) What are the factors that may affect their dynamic selection of the strategies in accordance with their identities in social interaction? It is expected to provide a new angle for dynamic discourse analyses in Chinese contexts.
\end{abstract}

\section{Introduction}

In using languages, people realize that in social interactions, the most universal way of recognizing a person's identity is by means of recognizing his or her speeches. Only through processing the speeches by minds can we establish individual identity so as to build our social images and strengthen the social positions acquired.

In social communication, the identity of the interlocutors forms one important part of the social relationship. The identity is the result of interpersonal consultation and interactions. Social members will more or less resort to language, including phonetics, lexicology, syntax, discourse structures and styles to express their ideas, attitudes, and values, etc. In this way, the interlocutors can establish their social identities explicitly or implicitly.

The relationship between language and identity has attracted wide attention among sociolinguists. The early sociolinguistic study took static approaches which could not provide a comprehensive explanation over the speech acts actualization in interpersonal interactions. The contemporary sociolinguistic studies stress the significance of using natural data and a variety of methodology to explore the relationship between language variations and social identities.

This study will take college students as research samples to explore systematically how the interlocutors accommodate to their social identities by adopting various strategies in social communication. College students are typically keen to pursue fashion and demonstrate their personality. So, exploring the strategies college students adopted in establishing their identities is of great significance to understand the function of language usage dynamically. 


\section{Theoretical Framework}

As one important part of sociolinguistics, Speech Accommodation Theory (SAT), was put forward by Howard Giles and others in the early seventies of the last century, which has become an interdisciplinary theory for explanation and analyses of sociolinguistic and psychological questions, communication study, pragmatics, as well as second language acquisition. ${ }^{[1]}$ The theory aims to provide an explanation why in face-to-face communication, the speakers accommodate constantly. The speakers tend to change the manner in which they speak dynamically depending on various factors, such as the attitude that speakers show towards each other, their language differences and their shared social contexts.

Accommodation can take the form of either convergence or divergence. Convergence and divergence are two linguistic strategies applied by the speakers and the addressees in social interactions. The two key concepts in SAT denote the different directions in which accommodation can occur in a speech interaction. Convergence indicates a linguistic process in which a speaker tends to modify his or her own speech to be more relevant to the addressee's speech, while divergence implies that in a speech interaction, the speaker takes an opposite linguistic way in order to make his or her speech sound quite distinct from what the addressee he or she is talking to. [2] The main ideas on convergence, divergence and speech maintenance in the SAT are supposed as a communication strategy. SAT has served as a cross-disciplinary framework for understanding the adjustments individuals make to create, maintain, or decrease social distance in interactions.

In this study, the dependent variables are strategies adopted by the college students in establishing their identities, and the independent variables are the social identities of the interlocutors.

In this study, the following questions will be explored and analyzed: (1) What strategies the college students will adopt in specific contexts to establish their identities? (2) What are the factors that may affect their dynamic selection of the strategies in accordance with their identities in social interaction?

\section{Dynamic Accommodation and Establishing Identity Strategies}

\section{Data Collection and Classification of Relationship}

The data quantified and analyzed in the study have been collected from 58 postgraduates I have taught in Wuhan University of Technology through two years (2015-2016), 29 females and 29 males involved. Natural observation method is adopted in collecting the data, which can guarantee the authenticity of the data recorded directly from the actual social interactions. Natural observation data are the conversations among those college students in their daily life, including complimenting, joking about the relationship problems, providing encouragement, offering advice, and relating others' experiences to their own similar experiences.

In order to get comprehensive data, the researcher encouraged the students to try to record the conversations as many as possible in their interpersonal interactions. Among students, four kinds of relationship are classified: same-sex friends, oppositesex friends, children vs. parents, and students vs. teachers. Through calculating, 686 conversations recorded from natural observation are evaluated valid for the analysis. 


\section{Speech Convergence and Identity Establishment}

According to Giles (2007), in bilingual contexts, the more effort in convergence a speaker was perceived to make, the more favorably the speaker was evaluated and the more the addressees would converge back in turn. [3] Convergence occurs when speakers accommodate or adjust their normal speech to make it more similar to their addressees' speech or to stereotype of it. Similar findings have been proved by Tajfel and Turner (1986) in their social identity studies. [4] Studies show that the mere act of individuals categorizing themselves as group members was sufficient to lead them to display in-group favoritism. After being categorized of a group membership, individuals seek to achieve positive self-esteem by positively differentiating their ingroup from a comparison out-group on some valued dimension. [5]

Linguistic choices are made with various degree of consciousness. Using language must consist of the continuous making of linguistic choices, consciously or unconsciously, for language-internal and/or language-external reasons. Speakers do not only choose forms but also choose strategies. Bell states that speakers will respond to the three aspects of their addressees' in deciding what adjustments to make: (1) their personal characteristics. (2) the general styles of their speed and (3) their use of specific linguistic features. So, in analyzing the dynamic process of speech accommodation, the three factors will be taken into account. [6]

To their peer groups, the college students tend to pay more attention to build solidarity with each other so as to achieve good communication and maintain a harmonious relationship. So, when speaking to their friends or classmates, the speaker will accommodate his/her speaking style to resemble the address' way of speaking consciously or unconsciously. Among students, solidarity can be established by common interest, similar experiences, shared values, etc. In communication with their friends or peers, the college students will try their best to accommodate their linguistic features to fit the contexts to create the comfort levels for others. Their linguistic features can be elaborated clearly from their tones of voice, stress, pronunciation, intonation, word forms, syntax, lexicons, etc.

After analyzing the data collected from 686 conversations concerning four relations, the researcher calculated the percentages of five topics among the four kinds of relationship. The following table 1 shows the detailed percentage of speech convergence in identity establishments among college students.

Table 1. Relationship and speech convergence shown in interpersonal communication

\begin{tabular}{|c|c|c|c|c|c|c|c|c|}
\hline Speech divergence & \multicolumn{2}{|c|}{$\begin{array}{l}\text { Same-sex } \\
\text { Friends } \\
\longleftarrow \longrightarrow \\
\text { Same-sex } \\
\text { Friends }\end{array}$} & \multicolumn{2}{|c|}{$\begin{array}{l}\text { Opposite-sex } \\
\text { Friends } \\
\longleftarrow \longrightarrow \\
\text { Opposite-sex } \\
\text { Friends }\end{array}$} & \multicolumn{2}{|c|}{$\begin{array}{l}\text { Children } \\
\stackrel{\longleftrightarrow}{\text { Parents }}\end{array}$} & \multicolumn{2}{|c|}{$\begin{array}{l}\text { Students } \\
\stackrel{\longleftrightarrow}{\longleftrightarrow} \\
\text { Teachers }\end{array}$} \\
\hline Complimenting & 21 & $15.5 \%$ & 15 & $15.3 \%$ & 9 & $9.6 \%$ & 11 & $13.9 \%$ \\
\hline Joking & 34 & $25.0 \%$ & 20 & $20.4 \%$ & 15 & $16.0 \%$ & 9 & $11.4 \%$ \\
\hline Providing encouragement & 23 & $16.9 \%$ & 30 & $30.6 \%$ & 17 & $18.1 \%$ & 20 & $25.3 \%$ \\
\hline Offering advice & 15 & $11.0 \%$ & 19 & $19.4 \%$ & 21 & $22.3 \%$ & 26 & $32.9 \%$ \\
\hline Relating to experiences & 43 & $31.6 \%$ & 14 & $14.3 \%$ & 32 & $34.0 \%$ & 13 & $16.5 \%$ \\
\hline Total & 136 & $100 \%$ & 98 & $100 \%$ & 94 & $100 \%$ & 79 & $100 \%$ \\
\hline
\end{tabular}

The humorous style of speeches is favored by college students, since it can create a relaxed atmosphere for the interlocutors and in this way, the comfort level of conversation will be promoted simultaneously. After analyzing the data, the 
researcher finds that homophonic expressions are preferred by students, especially for intimate relationships such as same-sex friends, girlfriends with boyfriends.

For instance, the mimetic term "bling-bling" is popularized among girls in their daily communication. They use the adjective phrase to describe something flashy, ostentatious, or elaborate. Since the term rises with hip hop culture, the usage of the word shows a trend of fashion, which is a core concept converged by students in their speech communication. Students use the term to demonstrate to others they are in style. This is one way of establishing their identities. When talking to their peers, both the same-sex groups and the opposite-sex groups tend to use humorous and relaxed style of expressions to create a light and easy-going atmosphere. Another example comes from the phrase "blah-blah-blah", which is adopted from a popular singer's song name.

The popularity of mimetic expressions, slangs and humorous styles of words among young people indicates that cultural diversity has motivated them to pursue fashion, to accommodate their speech or to shift their speaking strategies constantly to show their identities as members of this society.

\section{Speech Divergence and Identity Establishment}

In order to distinct him/her from others, speakers will show language variations consciously or unconsciously in social communication which are recognized as personal registers and personal styles. The register and style adopted by a speaker can not only reflect his/her identity, but also the requirements of actual language communication. If an individual does not bear his/her own personal characteristics in social interactions, his/her role in groups would eclipse gradually. Especially in this new era, with multiple social interactions, the speakers have to modify their registers and styles to accommodate with their various roles in diversified contexts.

After analyzing the data collected from 686 conversations concerning four relations, the researcher calculated the percentages of five topics among the four kinds of relationship. The following table 2 shows the detailed percentage of speech divergence in identity establishments among college students.

Table 2. Relationship and speech divergence shown in interpersonal communication

\begin{tabular}{|c|c|c|c|c|c|c|c|l|}
\hline Relations & $\begin{array}{l}\text { Same-sex } \\
\text { Friends } \\
\text { Speech divergence }\end{array}$ & $\begin{array}{c}\text { Opposite-sex } \\
\text { Fame-sex } \\
\text { Friends }\end{array}$ & $\begin{array}{c}\text { Friends } \\
\text { Opposite-sex } \\
\text { Friends }\end{array}$ & \multicolumn{2}{|c|}{$\begin{array}{c}\text { Children } \\
\text { Parents }\end{array}$} & \multicolumn{2}{|c|}{$\begin{array}{c}\text { Students } \\
\text { Teachers }\end{array}$} \\
\hline Complimenting & 37 & $43.5 \%$ & 26 & $28.5 \%$ & 12 & $19.7 \%$ & 6 & $14.3 \%$ \\
\hline Joking & 24 & $28.2 \%$ & 29 & $31.9 \%$ & 23 & $37.7 \%$ & 4 & $9.5 \%$ \\
\hline Providing encouragement & 7 & $8.3 \%$ & 5 & $5.5 \%$ & 6 & $9.8 \%$ & 16 & $38.1 \%$ \\
\hline Offering advice & 2 & $2.4 \%$ & 10 & $11.0 \%$ & 12 & $19.7 \%$ & 9 & $21.4 \%$ \\
\hline Relating to experiences & 15 & $17.6 \%$ & 21 & $23.1 \%$ & 8 & $13.1 \%$ & 7 & $16.7 \%$ \\
\hline Total & 85 & $100 \%$ & 91 & $100 \%$ & 61 & $100 \%$ & 42 & $100 \%$ \\
\hline
\end{tabular}

In analyzing the complimenting event, the researcher finds speech divergence more apparent in the complimenters' choice of strategies and the compliment responses from the addressees'. Female students tend to pay more attention to appearance, ornaments, clothing, hairstyles, etc. Among male students, with some compliments on the newly-acquired skills, capacities, and performance, a rising percentage of compliments among them relates to appearance, hairstyles, clothing. The research results show that quite contrary to the former hypothesis made In complimenting, 
both female students and male students tend to speak exaggeratedly to express their feelings by adopting charged adjectives and reinforced methods. For instance"

a. The complimenter: "You look so cool with your new hairstyle!"

(Plain Compliment)

b. The complimenter: "Wow! How handsome! Cool hair! Where did you cut it?"

(Comparatively Reinforced Compliment)

College students are typically keen to pursue fashion and demonstrate their individuality. So, exploring the strategies college students adopted in establishing their identities is of great significance to understand the dynamic functions of language use.

\section{Conclusions}

Dynamic accommodation is the core of SAT. The dynamics of using language and making choices has much to do with the language users' status, beliefs, interests, habits, and their self-recognition. They make accommodations in social interactions which can be actualized by the temporal, contextual and structural dimensions of language use. The process of accommodating in language uses will finally lead to the formation of an individual's social identity.

The research certifies that language does hold a function of establishing social identities. The case study on social identity establishment has further supplemented the study of language variation in linguistics and the theory of social construction in sociology. This research will enrich and deepen the understanding of multimode in linguistic field, and promote its application in teaching and linguistic studies.It is expected to enrich contemporary sociolinguistic studies and provide implications for further researches.

\section{Acknowledgement}

This research was financially supported by The Independent Innovation Foundation of Wuhan University of Technology.

\section{References}

[1] Howard Giles, Smith, Philip, Accommodation Theory: Optimal Levels of Convergence, in: Howard Giles, St. Clair, N. Robert (Eds.), Language and Social Psychology, Basil Blackwell, Baltimore, 1979.

[2] Information on https://en.wikipedia.org

[3] Howard Giles, Ogay, Tania, Communication Accommodation Theory, in: Bryan B. Whaley, W. Samter (Eds.), Explaining Communication: Contemporary Theories and Exemplars, Lawrence Erlbaum, New York, (2007)

[4] H. Tajfei, J. C. Turner, The social identity theory of inter-group behavior, in: S. Worchel, L. W. Austin (Eds.), Psychology of Intergroup Relations, Nelson-Hall, Chigago, (1986)

[5] Information on https://www.utwente.nl/cw

[6] A. Bell, Language Style as Audience Design, Language in Society, 13(1984).

[7] J. Verschueren, Understanding Pragmatics, Arnold, London and New York, 1999. 